\section{AB1367 DIAGNOSTIC ASSOCIATION BETWEEN ELASTIN AND ELASTASE ANTIBODIES WITH CARDIOVASCULAR SYSTEM INVOLVEMENT IN SYSTEMIC SCLERODERMA PATIENTS}

I.P. Gontar ${ }^{1}$, O.A. Rusanova ${ }^{2}$, O.I. Emelyanova ${ }^{1}$, L.A. Maslakova ${ }^{1}$, I. A. Zborovskaya ${ }^{1} .{ }^{1}$ Reserch Institute of Clinical and Experimental Rheumatology named after A.B. Zborovsky; ${ }^{2}$ Research Institute of Clinical and Experimental Rheumatology named after A.B. Zborovsky, Volglgrad, Russian Federation

Background: Large amounts of elastin are contained in vascular walls and in the cardiac valves. Elastin and elastase antibodies are predictors, sui generis, of vascular disease development in systemic scleroderma. The mechanism of direct proatherogenic effect of antibodies consists in stimulation of adhesion molecules and cytokine synthesis, oxLDL capture, induction of serine proteinase cascade by the coagulation system. In systemic rheumatoid disease, autoimmune inflammation is nowadays regarded as one of risk factors for the development of early atherosclerosis, disturbance of the structure and elasticity of vascular wall and of related cardiovascular conditions.

Objectives: Studying the effect of elastin and elastase autoantibody production on the cardiovascular system in systemic scleroderma (SSD) patients.

Methods: 42 patients hospitalised at municipal hospital 25 with diagnosis of SSD verified by ; ARA diagnostic criteria (1980) the diagnosis was considered firm if the patient showed one major and two minor criteria in any combination, simultaneously or consecutively, regardless of the time of their onset. The systemic scleroderma patients included 11 men and 31 women aged 22-72. The mean age of patients was $44.1 \pm 15.4$ years. 30 healthy donors from the Volgograd hemotransfusion centre served as controls. Antibodies to elastin and elastase were determined in the blood serum using indirect enzyme immunoassay with magnetocontrolable adsorbents based on polyacrylamide granules according to the original technique by. Gontar et al (1990)

Results: SSD patients showed considerable increase in the rate of elastase $(52 \%)$ and elastin (38\%) antibodies formation, in comparison with the controls. The upper normal limit of elastin antibody was within the range of 0.131 optical density units, elastase antibodies -0.131 optical density units. In SSD patients elastin antibodies amounted to $0.125 \pm 0.068$ optical density units. The titer of elastase antibodies was $0.143 \pm 0.071$ optical density units. Healthy individuals did not show any elastin or elastase antibodies. An elevated antibody titer was associated with heart and vessels lesion in $47 \%$ of patients with SSD. In 20 patients of the studied group we revealed cardiovascular disease (IHD, macrofocal cardiosclerosis with false infarction changes, chronic cardiac failure, and aorta atherosclerosis).

Conclusions: Among the patients we examined, $47 \%$ showed cardiovascular lesion associated with elevated elastin and elastase antibodies. This fact indicates that in systemic rheumatic disease, autoimmune inflammation is a risk factor for the development of early atherosclerosis, and of related cardiovascular conditions. Elastin and elastase antibodies are predictors, sui generis, of the development of vascular disease in patients with SSD.

Disclosure of Interest: None declared

DOI: 10.1136/annrheumdis-2018-eular.4480

\section{AB1368 THE COMPARATIVE RESPONSIVENESS OF HOSPITAL UNIVERSITARIO PRINCESA INDEX AND OTHER COMPOSITE INDICES FOR ASSESSING RHEUMATOID ARTHRITIS ACTIVITY}

1. Gonzalez-Alvaro ${ }^{1}$, I. Castrejon ${ }^{2}$, L. Carmona ${ }^{3} .{ }^{1}$ Rheumatology, Hospital Universitario La Princesa. IIS-IP, Madrid, Spain; ${ }^{2}$ Rheumatology, Rush University, Chicago, USA $;{ }^{3}$ Rheumatology, InMusc, Madrid, Spain

Background: HUPI was developed with data from the PEARL study (Princess Early Arthritis Register Longitudinal study) as an easy to calculate index, which avoided the gender bias affecting DAS28 and SDAI. In addition, it can be calculated either with erythrocyte sedimentation rate (ESR), C reactive protein (CRP) or both. Response criteria based on HUPI have also been developed ${ }^{1}$.

Objectives: To evaluate the responsiveness of the Hospital Universitario La Princesa Index (HUPI) comparatively to the traditional composite indices to assess disease activity in rheumatoid arthritis (RA), and to compare the performance of HUPI-based response criteria with that of the EULAR response criteria.

Methods: Post-hoc analyses were performed using data from the following studies: ACT-RAY (clinical trial), PROAR (early RA cohort) and EMECAR (pre-biologic era long term RA cohort). Responsiveness was evaluated by: 1) comparing change from baseline $(\Delta)$ of HUPI with $\Delta$ in other scores by calculating correlation coefficients; 2) calculating standardised effect sizes. The accuracy of response by HUPI and by EULAR criteria was analysed using linear regressions in which the dependent variable was change in global assessment by physician ( $\triangle$ GDA-Phy). Results: $\triangle \mathrm{HUPI}$ correlation with change in all other indices ranged from 0.387 to 0.791); HUPI's standardised effect size was larger than those from the other indices in each database used. In ACT-RAY, depending on visit between $65 \%$ and
$80 \%$ of patients were equally classified by HUPI and EULAR response criteria. However, HUPI criteria were slightly more stringent, with higher percentage of patients classified as non-responder, especially at early visits. HUPI response criteria showed a slightly higher accuracy than EULAR response criteria when using $\triangle$ GDA-Phy as gold standard.

\begin{tabular}{|c|c|c|c|c|c|c|c|c|}
\hline \multicolumn{9}{|c|}{ Comparison of sensitivity to change HUPI with other composite indices. } \\
\hline & \multicolumn{5}{|c|}{ Standardised size effect } & \multicolumn{3}{|c|}{$\begin{array}{c}\text { Response (\%, EULAR vs } \\
\text { HUPI) }\end{array}$} \\
\hline & HUPI & $\begin{array}{c}\text { DAS28- } \\
\text { VSG }\end{array}$ & $\begin{array}{c}\text { DAS28- } \\
\text { PCR }\end{array}$ & SDAl & CDAl & None & Moderate & Good \\
\hline 3 months & 2'3 & 2'18 & 2'2 & $1999^{*}$ & $17^{*}$ & $\begin{array}{c}9 \text { vs } \\
22\end{array}$ & 53 vs 42 & $\begin{array}{c}38 \mathrm{vs} \\
36\end{array}$ \\
\hline $\begin{array}{l}6 \\
\text { months }\end{array}$ & $3^{\prime} 13$ & $2 ' 93$ & 2'85 & $2^{\prime} 56^{*}$ & $27^{\prime}$ & $\begin{array}{c}3 \text { vs } \\
9{ }^{\prime} 5\end{array}$ & 34 vs 29 & $\begin{array}{l}63 \text { vs } \\
6055\end{array}$ \\
\hline $\begin{array}{l}12 \\
\text { months }\end{array}$ & 3'69 & $3^{\prime} 45$ & $3^{\prime} 28^{*}$ & $2 \cdot 87^{*}$ & $2^{\prime} 65^{*}$ & $\begin{array}{l}2 \text { vs } \\
655\end{array}$ & 23 vs 20 & $\begin{array}{c}75 \text { vs } \\
73^{\prime} 5\end{array}$ \\
\hline
\end{tabular}

${ }^{*} \mathrm{p}<0.05$ respect HUPI

Conclusions: HUPI shows good responsiveness in each studied scenario (clinical trial, early RA cohort, and established RA cohort). Response criteria by HUPI seem more stringent than EULAR's.

\section{REFERENCE:}

[1] Gonzalez-Alvaro I, Castrejon I, Ortiz AM, Toledano E, Castaneda S, Garcia-Vadillo A, et al. Cut-Offs and Response Criteria for the Hospital Universitario La Princesa Index (HUPI) and Their Comparison to Widely-Used Indices of Disease Activity in Rheumatoid Arthritis. PLoS One. 2016;11(9): e0161727.

Acknowledgements: We are endebted to the Roche laboratory for the transfer of the ACT-RAY trial data and to the Spanish Rheumatology Society for the transfer of data from the EMECAR and PROAR projects. Without the work of all the researchers who participated in these three projects, this work could not have been developed. This work has been supported by project PI14/00442 to IG-A from the Ministry of Economy and Competitiveness (Carlos III Health Institute) and co-financed with the European Fund for Regional Development (FEDER). Disclosure of Interest: I. Gonzalez-Alvaro Grant/research support from: UCB Roche., Consultant for: Lilly, Pfizer, BMS, Sanofi, Speakers bureau: Abbvie, Lilly, UCB, SER, I. Castrejon: None declared, L. Carmona: None declared DOI: 10.1136/annrheumdis-2018-eular.4479

\section{AB1369 ELEVATED CA-125 IN IGG4-RELATED MESENTERIC DISEASE: A RED HERRING? A SYSTEMATIC LITERATURE REVIEW}

1. Panayotidis ${ }^{1}$, M. Michaud Maturana ${ }^{1}$, S. Psarelis ${ }^{2}$, E. Nikiphorou ${ }^{3} .{ }^{1}$ Medical School, University College London (UCL), London, UK; ${ }^{2}$ Rheumatology Department, Nicosia General Hospital, Nicosia, Cyprus; ${ }^{3}$ Department of Academic Rheumatology, King's College London, London, UK

Background: Mesenteric panniculitis (MP), a rare fibrotic inflammatory disease of the bowel mesentery, can be a rare manifestation of IgG4-related disease (IgG4-RD). IgG4-RD is a chronic inflammatory disease most commonly affecting the pancreas, characterised by infiltration of IgG4-positive plasma cells and lymphocytes into various organs.

We recently encountered a male patient with lgG4-related MP who was incidentally found to have a very high level of CA-125, which correlated with CRP levels and normalised after steroid treatment. This prompted a systematic literature review (SLR) to better understand this unexpected phenomenon.

Objectives: To investigate for associations between CA-125, MP and/or IGG4$\mathrm{RD}$, understand possible common pathophysiological mechanisms and explore potential clinical implications.

Methods: The SLR was performed using MEDLINE, EMBASE, Web of Science, and Scopus, looking for literature on either MP and CA-125 or IgG4-RD and CA125 up to January 82018 , using a comprehensive search strategy with relevant mesh terms and keywords linked to the above broad categories. Literature screening was performed by two independent reviewers.

Results: 24 unique citations were found, of which 13 were unanimously identified as relevant by the two reviewers. The final selected articles included: 8 case reports, 3 conference abstracts of case reports, 1 cohort study of 22 patients, and a retrospective study of 7 patients (table 1). CA-125 was raised in 22/40 patients in the identified reports (shown in red), including males, and was often the only elevated tumour marker (yellow). We also report on the presence of effusions (blue), as this may be linked to the causal mechanism.

Table 1 The clinical and laboratory characteristics of cases of IgG4-RD and MP 